\title{
Proposal for Design and Application of Business Intelligence as a Decision Support System to the Editorial Sector of Distance Education (DE)
}

\author{
Walther Azzolini Junior \\ State University of São Paulo, São Carlos, Brazil \\ José Luís Garcia Hermosila, Luciano Bérgamo, Lucas Lima \\ University Center of Araraquara, Araraquara, Brazil
}

\begin{abstract}
In recent years, industrial and service organizations have invested in improvement projects with emphasis on increasing the performance of processes regarding to the production of manufactured goods and services, applying techniques to optimize production time in order to minimize the restrictive effects of the funds invested in processing or obtaining processes in order to reduce the losses of general scope. This paper discusses the impact of the innovation in making use of business intelligence (BI) concepts about production records of a publishing area in a higher education institution (HEI) that promotes distance education (DE) in Brazil, helping the industry in their managements decisions, having a target minimize time on production of learning material through more effective control with the use of cubes in the form of reports for metric queries of delivery delays and metrics on the production tasks financial values, and filtering the processed information so that managers can view information from various angles and managerial perspectives. The objectives of this paper are to demonstrate the impact on using BI concepts in the process of an editorial department of a HEI focusing on the development of teaching materials for the courses of DE and identify the financial cost-benefit ratio for the HEI with the deploying BI in a software fee platform in its publishing department. The sector is responsible by in courseware publishing organizations that usually do not have systems with this emphasis: support on making managerial decisions.
\end{abstract}

Keywords: business intelligence, data warehouse, distance education (DE), free software and open source software, open source, Pentaho

\section{Introduction}

Bose (2006) described that companies, like Continental Airlines and First American Corporation, have invested in implementing successful business intelligence (BI) models to improve their loyalty with customer

Walther Azzolini Junior, professor, University of São Paulo (USP) School of Engineering of São Carlos, State University of São Paulo at São Carlos, Brazil.

José Luís Garcia Hermosila, professor, University Center of Araraquara, Araraquara, Brazil.

Luciano Bérgamo, student of the master's program in production engineering, University Center of Araraquara, Araraquara, Brazil.

Lucas Lima, student of the master's program in production engineering, University Center of Araraquara, Araraquara, Brazil.

Correspondence concerning this article should be addressed to Walther Azzolini Junior, University of São Paulo (USP)/School of Engineering of São Carlos, State University of São Paulo at São Carlos, Av. Trabalhador São-carlense, 400 13566-590 São Carlos, SP Brazil. 
and increase return on investment.

Kim (2007) pointed out the importance of information systems as a mandatory liability of a company, making it necessary for their management and survival.

According to Kim (2007), in industrial information systems, e-mails, instant messages, database queries, and accessed internet content are critical business records that must be protected, monitored, maintained, recovered, and controlled.

According to Watson and Wixom (2007), BI is a process that includes two primary activities:

(1) getting data in and getting data out: Getting data in, traditionally referred to as data warehousing, involves moving data from a set of source systems into an integrated data warehouse;

(2) getting data in delivers limited value to an enterprise; only when users and applications access the data and use it to make decisions does the organization realize the full value from its data warehouse. Thus, getting data out receives most attention from organizations.

The second activity to Watson and Wixon (2007), which is commonly referred to as BI, consists of business users and applications accessing data from the data warehouse to perform enterprise reporting, online analytical processing (OLAP), querying, and predictive analytics. In this case, this paper discusses the need for the designing of business processes which should support the BI software as an expert in the decision-making process and should signal likely scenarios in which you can reduce operationally production costs.

Phan and Vogel (2010) pointed out that in the face of rapid advances in technology, companies are often looking for new ways to establish value positions, confirming the need of BI to succeed in relationship management system with customers. Azmaa and Mostafapourb (2011) explained that during the first decade of the 21 st century, the approach to business with emphasis on management around the world has changed profoundly and organizations have been able to shape the information in the knowledge format, supporting by BI as a critical strategy for any organization to achieve a competitive advantage. According to Azmaa and Mostafapourb (2011), intelligent information with BI makes a company or organization to be able to adapt to business changes.

Organizations can use BI within the scope of their information technology (IT) project to collect data and analyze them. Managers can make good decisions, reducing additional costs by improving the performance and productivity (Azmaa \& Mostafapourb, 2011). Castellanos, Gupta, Wang, and Daya (2012) pointed that the companies are hoarding and overlapping a lot of unstructured data at the source. Therefore, there is a need for information systems to consolidate scenarios from these data in order to get support for the reflection of the strategies of business.

Castellanos et al. (2012) pointed out that in the context of an organization, the ability to extract valuable information from all types of data (i.e., structured, semi-structured, and unstructured) and act immediately, supports decision-making that provides a huge competitive advantage.

Heiner (2013), making eight interviews in eight industrial companies to explore the architectures of IT, realized the importance of identifying data sources and developed a BI model as a support on decisions for production engineering.

Heiner (2013) showed the need for greater maturity in production engineering, pointing the application of the BI concept to match the information about the product characteristics and of the production system in order to identify the impacts related with the engineering decisions about the life cycle of the product. 
Organizations should also consider the need of incorporating the necessary flexibility in decision-making processes supported by BI, even for structured operational decisions (Isik, Jones, \& Sidorova, 2013).

A. Rubin and E. Rubin (2013) argued that the deployment of BI systems and their functionality must reduce the risks associated with holding industrial stock, generating a positive return for the company. Isik et al. (2013) explained that organizations tend to fail by not prioritizing data quality and BI systems, not realizing that their decisions are hindered by insufficient data.

For Mcbride (2014), data are irrefutable, indisputable, and scientifically accurate. Decisions are considered scientific and objective, as supported by visibility obtained through the use of BI.

The structure and the computational resources of BI refer to information technology projects (ITP) with emphasis on organization and processing of large databases in order to support the decision process of business guidelines. The data sources can be both internal and external. The data can be accessed and processed in a database (Mcbride, 2014).

In this scenario, starting from the collection of a database containing records of an information system in the publishing industry of IES, the author of the present study sought to answer:

(1) How can a BI free software help the operational management of DE with an emphasis on editorial process?

(2) How can the use of concepts related to design a BI software support the decision-making process within the context of educational material publishing process of DE?

This paper discusses the development of a BI model applied to DE, comprising, in this extended abstract, the following sections: section 2-BI applied on DE; section 3-free and open source software; section 4-BI construction; section 5-production system on the publishing department and considerations; and section 6 - discussion and analysis of responses.

\section{BI Applied to DE}

DE, for example, can be benefitted from the use of BI, because it is a teaching method in which students are physically separated from educators and the monitoring and management of the entire operation require the use of technology IT with a certain level of sophistication. The DE systems are used in most universities in Turkey and Northern Cyprus (Kaya, 2012).

According to Sen and Ucar (2012), DE has many advantages, including the use of multimedia tools and techniques to quickly access content over the internet, increasing user student interaction and providing the acceptance of DE.

D. Agdas, Washington, Ellis, S. Agdas, and Dickrell (2011) studied a master's program in civil engineering at a US university in DE format that allows students to work full-time while still meeting their responsibilities with the studies and activities to be developed within the scope of DE.

Seven, Çinar, Fidancı, and Akyüz (2014) applied a questionnaire to 238 nurses in Turkey and have noted that $56.7 \%$ of respondents said that they only had access to the latest developments of methods and procedures related to the field of nursing through distance learning and therefore support the creation of new courses in DE platform.

The DE is taught through didactic material. In courseware production process, the professors provide the contents and the multimedia production team performs all the process of review and editing ( $\mathrm{Gao}, \mathrm{Li}, \mathrm{Xiao}, \&$ Wan, 2012). 
Gao et al. (2012), researching the current state of development of DE in China, concluded that, due to the rapid development of this sector, there is a need for trained teachers to produce more and better teaching materials and specific software for DE.

Lenar, Artur, Ullubi, and Nailya (2014) reported experiences with DE in Russia and stated that the main technique adopted by the Russians in DE is summarized in the creation of educational information environment, including sources of information and electronic libraries, videos, audio collections, books, and manuals.

Lenar et al. (2014) also emphasized that the ideal model of DE is represented by an integrated environment, with defined functions of various components and organizational, pedagogical, and technological methodology, as well as print media, radio, television, and the computers.

However, it is important to highlight the work of Kutluk, Gulmez, and Sidorova (2012) that when performing a satisfaction research on DE at two universities in Turkey, they summarized that the students in the time were dissatisfied with the distance education system (DES), pointing flaws in education and offering suggestions for improvement.

Among the weak points, Kutluk et al. (2012) pointed out students' difficulties in learning with multimedia materials and also in the interaction with tutors. The digital publication of the DE learning materials changes the whole process of production and editing, supported in areas, such as technical infrastructure, content organization, design and graphics, accessibility, content management, web publishing, archiving, and digital rights (Hunter, 2013).

Hunter (2013) in his research on DE made a series of questions, highlighting two:

(1) How are the service departments changing to accommodate digital publishing initiatives?

(2) What strategies are managed to change departments to support digital publishing?

Lin, Chiou, and Huang (2013), comparing the sales of digital publications between the United States and Taiwan, stressed that Taiwan is lagging behind in this market and stated initiatives for the digital industry, supporting authorization contracts and agreements for authors among publishing houses to edit new digital content to represent the major constraint.

Hunter (2013) investigated 26 university libraries. When compiling the survey data, he understood that there must be management plans for technical maintenance of digital publishing platforms and formatting and editing content published digitally.

Environmental sustainability has become a common goal in the global community. Organizations, especially in manufacturing, are responsible for the protection of the environment and sustainability (Chou, 2013).

Nowadays, there is much discussion about green IT, as a concept in the use of information technology focused on caring about the environment. Faucheux and Nicolaï (2011) defined green IT as an industry activity and its impact on environmental efficiency and the impact of IT on environmental productivity of other sectors.

The publishing sector covered in this paper has directed its production of media content focusing on the internet, with the support in Green IT.

According to Faucheux and Nicolaï (2011), the green IT services are truly able to reduce the impact on global environment and especially to create a structural change, allowing economic growth and climate change.

\section{Free Software and Open Source Software}

"Free software" should be understood as a software that respects the freedom and the sense of community of its users. According to common sense, users have the freedom to run, copy, distribute, study, change, and 
improve the software (Stallman, 2015).

The writing, editing, proofreading, translation, presentation, and disclosure require an effort that someone has to do, but with a considerable cost (Aliaga, 2014).

According to Pimentel and Silva (2014), in the case of intellectual property rights of computer programs, the authors pointed out that between the free software and the other "not free" applications, they relied the non-exclusive exercise of the rights holder, constant commitment under the free distribution pact of the software. "Free software" awards four freedoms:

(1) the freedom to run the software for any purpose (for example, in education or business);

(2) the freedom to study and adapt the software to their own needs;

(3) the freedom to redistribute the software;

(4) the freedom to improve the program and release public improvements (Steiniger \& Hunter, 2012).

Yu, H. J. Yang, Kuo, and H. H. Yang (2012) considered that the economic viability of free software has been recognized by major corporations, such as IBM, Red Hat, and Sun Microsystems as well; many companies are choosing free software because of the lower initial capital investment.

Steiniger and Hunter (2012) presented open source, as a kind of free software whose source code is accessible, therefore pointing the acronym FOSS - free and open source software.

Since 1997, a reasonable number of meetings have taken place, contributing too many debates on the role of free and open software in countries around the world, including China, France, and the Netherlands.

However, of all countries, only Brazil has decided to implement effectively both at the deepest levels of public administration (Silva \& Almeida, 2009).

Silva and Almeida (2009) also added that the Brazilian government created a free software committee that assists in the implementation of free and open software to the Ministries Culture, Science, and Technology and also for the Brazilian Army and Brazil's Navy.

Companies are also creating solutions using open source and free software systems and a large part of Brazil's society is aware of the facts that are getting stronger and will become part of the life of a significant portion of the Brazilian society (Silva \& Almeida, 2009).

\section{Construction of BI}

The BI proposed in this paper is structured from seven processes outlined by the authors, as follows:

(1) process 001 (Figure 1) - hiring the authors, handouts mediational validators after indication of the course coordinators;

(2) process 002 (Figure 2) - attend demands: production system publishing sector;

(3) process 003 (Figure 3) - run the editorial process of handouts mediational;

(4) process 004 (Figure 4) - managing the demands review;

(5) process 005 (Figure 5) - review handouts mediational;

(6) process 006 (Figure 6) — diagram the handouts mediational (1);

(7) process 007 (Figure 7) — diagram the handouts mediational (2).

\section{Hiring the Authors}

The process 001 (Figure 1) shows the flow of information on procedures performed from the author's contact teaching material of the Law College sector. 
Before this procedure, it is understood that the course coordinator has already made a first contact with the author.

It is understood that the publishing department has also been in contact to explain the working model of the institution according to Figure 1.

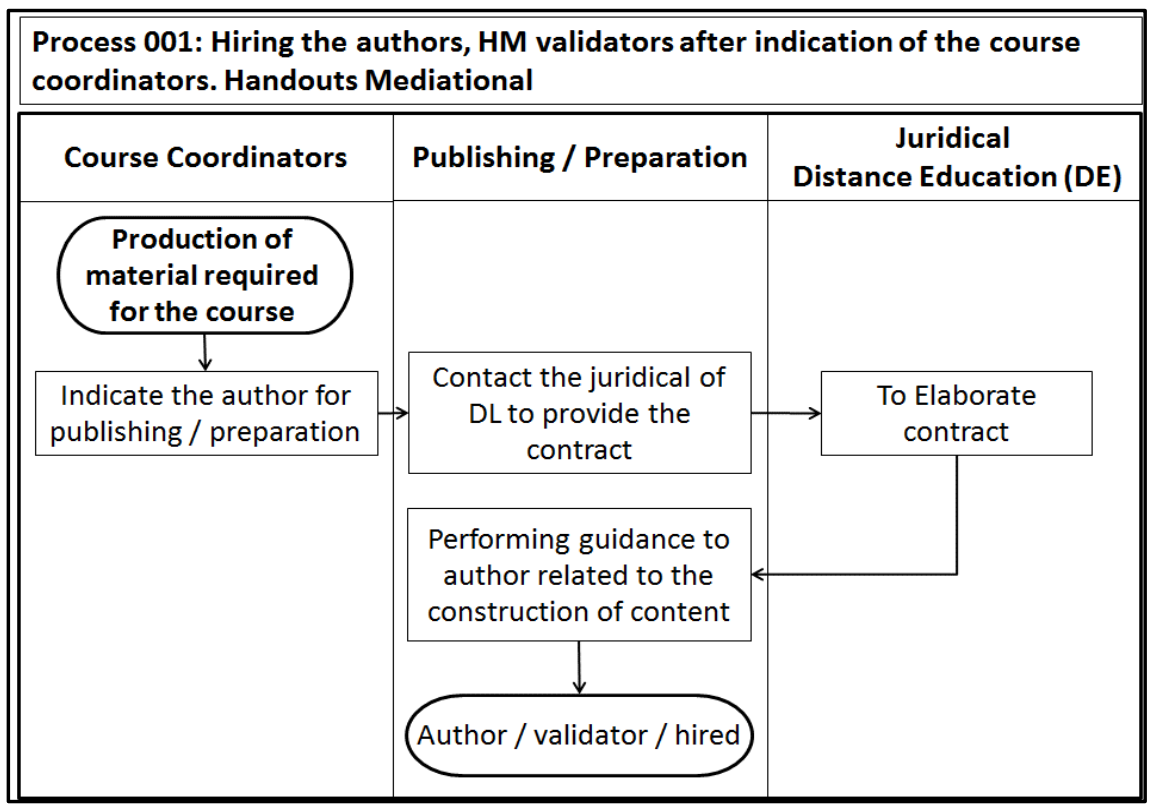

Figure 1. Process 001. Source: Surveyed-higher education institution (HEI).

\section{Production System Publishing Sector}

In theory, all handouts mediationals are didactic and pedagogical productions and can be configured as academic productions, but not all of them can be considered as technical and scientific academic productions.

A handouts mediational can be considered as academic-scientific production as long as it is set as an original work, unprecedented and regulated by copyright agreement, in which the authors gave a new meaning to the data and information in order to set up a new conceptual territory.

Among the categories produced by the institution, are the textbooks, the basic contents of reference, the video lecture material, supplementary videos, and handouts.

Thus, the elaboration of didactic content involves relevant issues related to the copyright act as: originality, novelty, intellectual property, property ownership, improper reproduction, and use of future work, which among others, are adjectives that define a work or a production in technical and scientific academic.

The construction, reproduction, and distribution logistics of educational content for higher courses in DE is a complex process that not only demands learning methods and specialized teaching resources, but also requires technical and pedagogically skilled staff, implying high operating costs for the institution.

Adding to this is the operation of the courses and the infrastructure. An educational project distance learning (DL) is only possible because of a clear institutional-political will, consistent and combined with an explicit and implicit commitment of the interacting subjects that can give sustainability to the implementation of DE.

Among the scholar produced products, stand out the followings: academic guide, education plan, content reference book; notebook activities and interactivities, practice pad, stage pad, video-class, and podcasts. 
Following are the descriptions of each of the products:

- Academic guide offers the student an overview of the course, providing information and guidelines and practices on the course on the teaching methodology, evaluation processes, telematics resources, libraries, and channels of communication between the student and the institution;

- Teaching plan contains the general objective of the course, the menu, the skills and abilities to be acquired, as well as the basic and the supplementary bibliographies. You can also find in this product a detailed description of all activities, interactivity and practical work to be performed in each study week of the semester, showing the study schedule for each subject in accordance with the learning cycles;

- Content reference book brings the syllabus of instructional units. Before studying the content of the course, the student is guided and introduced on the topics of study methodology. In textbooks, items that measured the student and the institution are components of great importance;

- Practice notebook indicates the project that the student must perform to make up the practice of design in their curriculum hours of practice as a curricular component;

- Internship notebook is aware of the student about the importance of training for their professional practice and provides the necessary guidance on how to proceed regarding this educational practice;

- Video lessons are recorded by teachers in their own studio on the institution that are available in the virtual environment;

- Podcast are lessons audio recorded and made available in the virtual learning environment.

All of these components are anchored in a virtual learning environment developed (programmed) and maintained by the institution.

The profile of the student DE is distinguished from the traditional classroom student, since he works and has autonomy and his own decisions, study on his own time and anywhere. Handouts mediational should meet this need.

The company builds its own handouts mediational, trying to preserve the principles of pedagogical and web usability, not only regarding the criteria of qualities as coverage, density, and depth, but above all, accessibility, portability, and mediation between the student and the institution.

In this case, the criteria for evaluating of the content of teaching material of distance learning must be defined by the coordinator of the area of knowledge to which the course that is being offered belongs.

The process 002 presents a line of macro processes starting with the request of the handouts mediational, which is usually made by the course coordinator and then the publishing center leader analyzing the level of work and the people who will carry it out, according to the editorial precepts cited above.

The concern with the handouts mediational's quality is constant. Your content should be promoted not only on bringing data and information on the topic covered, but also on taking care of persuasion, the motivation of the student, the contextualization of information, saying, informing, and ensuring the arguments, raising questions, illustrating and summarizing content, encouraging reflection, and redefinition of the contents.

In this teaching format, the teacher has a DL tutor function and is responsible for facilitating contact between the student and the handouts mediational in a way as simple, clear, and didactic as possible.

Handouts mediational is the promoter of a set of activities and interactivity that should guide the student, through mediation and interaction with an efficient tutoring, to the construction of knowledge and the acquisition of skills and abilities inherent in the desired configuration by the student. 
After the first version of MDM has passed by the editorial and layout, the course coordinator evaluates and decides to approve or not to approve the material according to Figure 2, completing the final stage of approval of the teaching material.

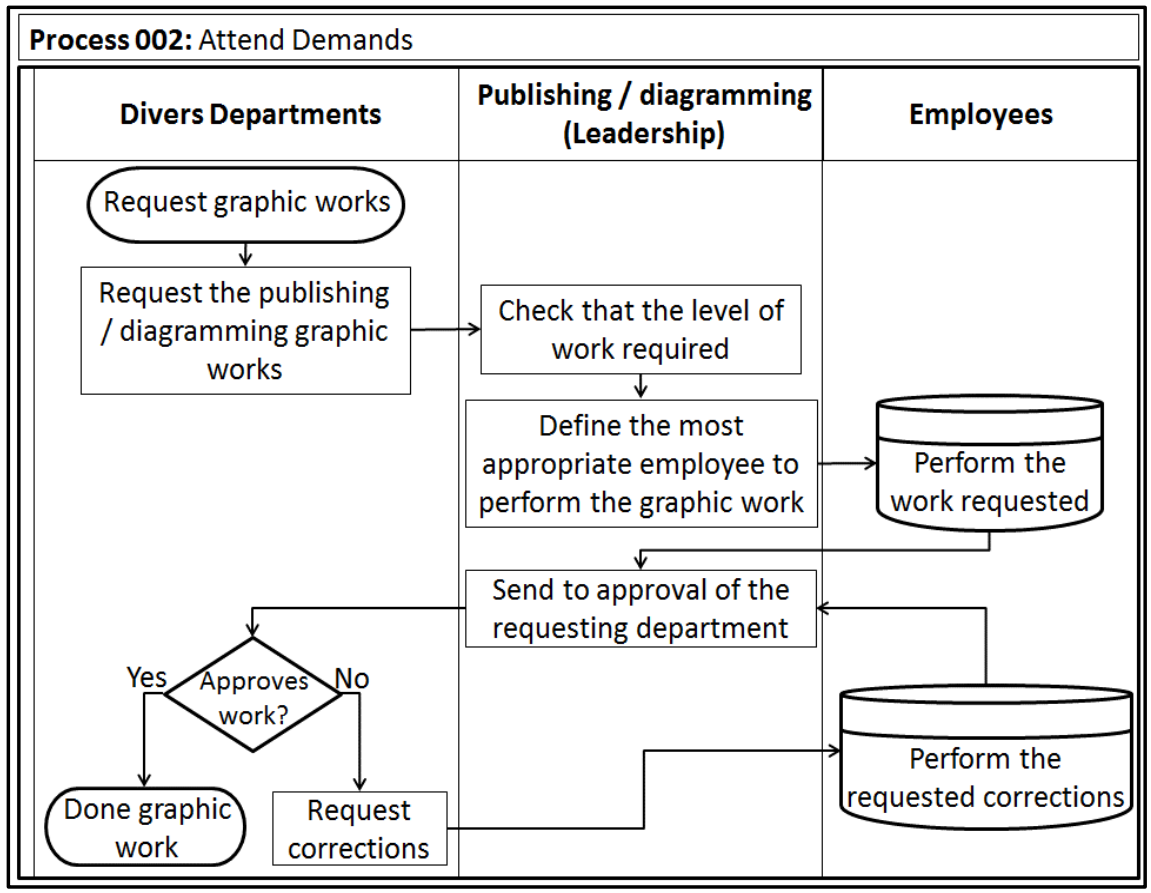

Figure 2. Attend demands-Production system publishing sector. Source: Surveyed-higher education institution (HEI).

\section{The Production Department}

The sector of editorial of higher education institution (HEI) is responsible for the production of handouts mediational and is divided into four sections: publishing, review, design, and legal.

\section{The Center of Publishing}

The center of publishing is formed by designers and area coordinators in charge of managing the production of the course handouts mediational under their responsibility, so that the printed or digital material can come up with the necessary quality and on time in the hands of students.

It is responsible for monitoring all the editorial process from the preparation of the text by the author and validation, as well as pedagogical preparation of the contents and the revision of artwork, after going through the review and layout.

The process 003 emphasizes that upon receiving the material of the author, a sequence of editorial processes for analysis and processing of information begins, making the form educational and accessible to students. Soon after, the material is sent for review and then returned to the author.

The authors made a review of the improvements and then handouts mediational is routed to the design and finally made available to the student according to Figure 3.

\section{Review Center-Managing the Demands Review}

The process 003 (Figure 3) describes the management control of the editing procedure as the primary format according to the standard of teaching material structure defined by the editorial staff. 
The handouts mediational is forwarded to the leader that checks the priority, sets the team activities, and inserts the review plan schedule on the planning system.

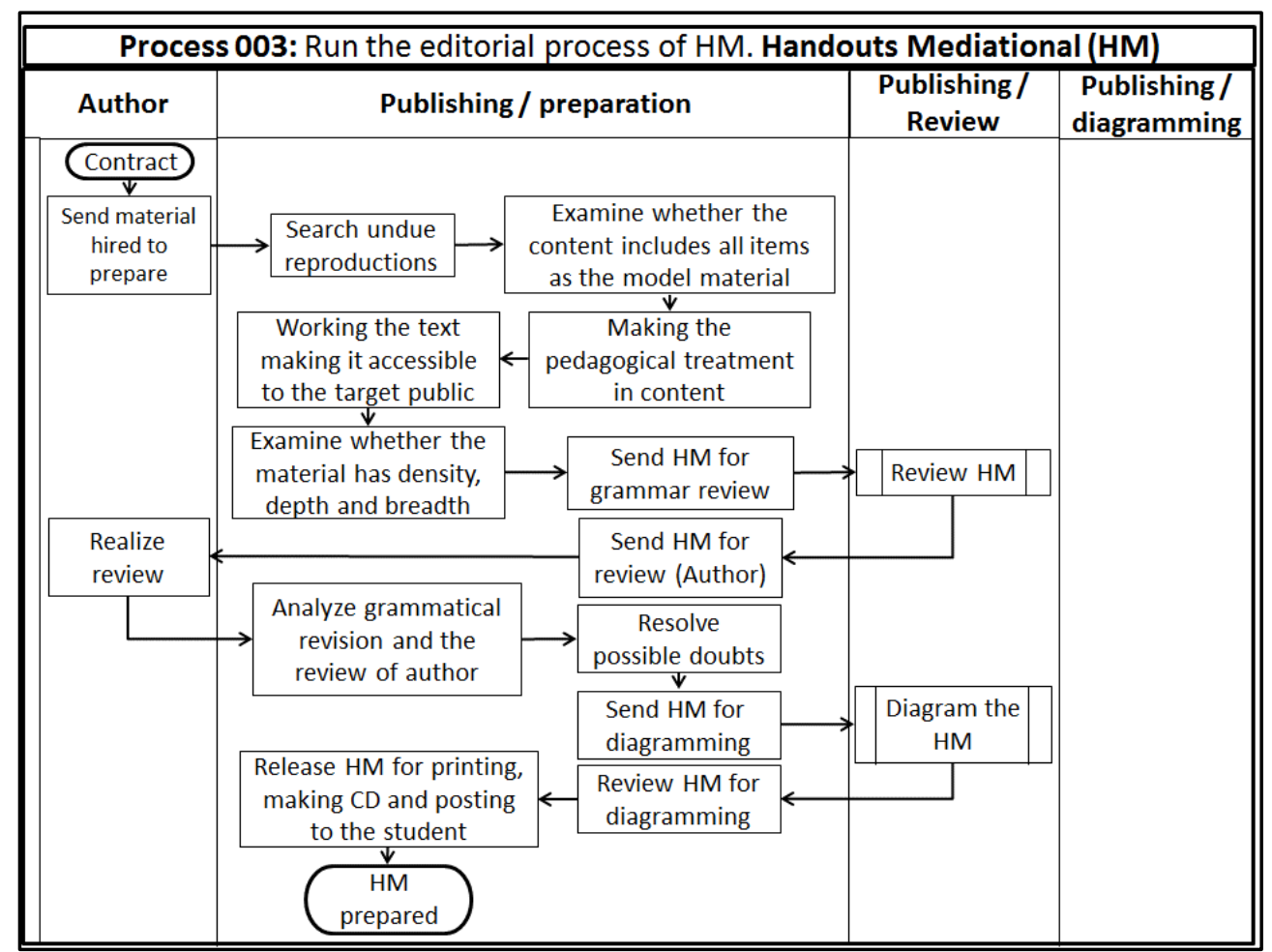

Figure 3. Run the editorial process of handouts mediational. Source: Surveyed — higher education institution (HEI).

This leader also monitors the process until its conclusion, in accordance with Figure 4. The review center is constituted by the reviewers.

They are responsible for the processing of language: standardization and grammar of texts. The text should be presented in simple language and easy to understand. Coherence, conciseness, and textual cohesion are essential qualities in a textbook.

\section{Review Handouts Mediational}

The process 004 shows the review core of tasks that permits consulting the progress of the review process, giving low in accordance with the completion of milestones described in the system and forwarding the handouts mediational to the core of diagramming, according to Figure 4.

It is formed by visual designers and web designers.

They take care of the visual-graphic designs, digital layout, and the addition of new features to the media materials.

Your challenge is to build a handouts mediational design geared to new technologies that adds graphics and media facilitators of learning; a handouts mediational that presents portability and web usability being cost-effective, within the institutional conditions.

\section{Core of Diagramming}

The process 006 presents the layout of the center' activities by checking the version of handouts mediational, diagramming and saving the material according to Figure 6. 


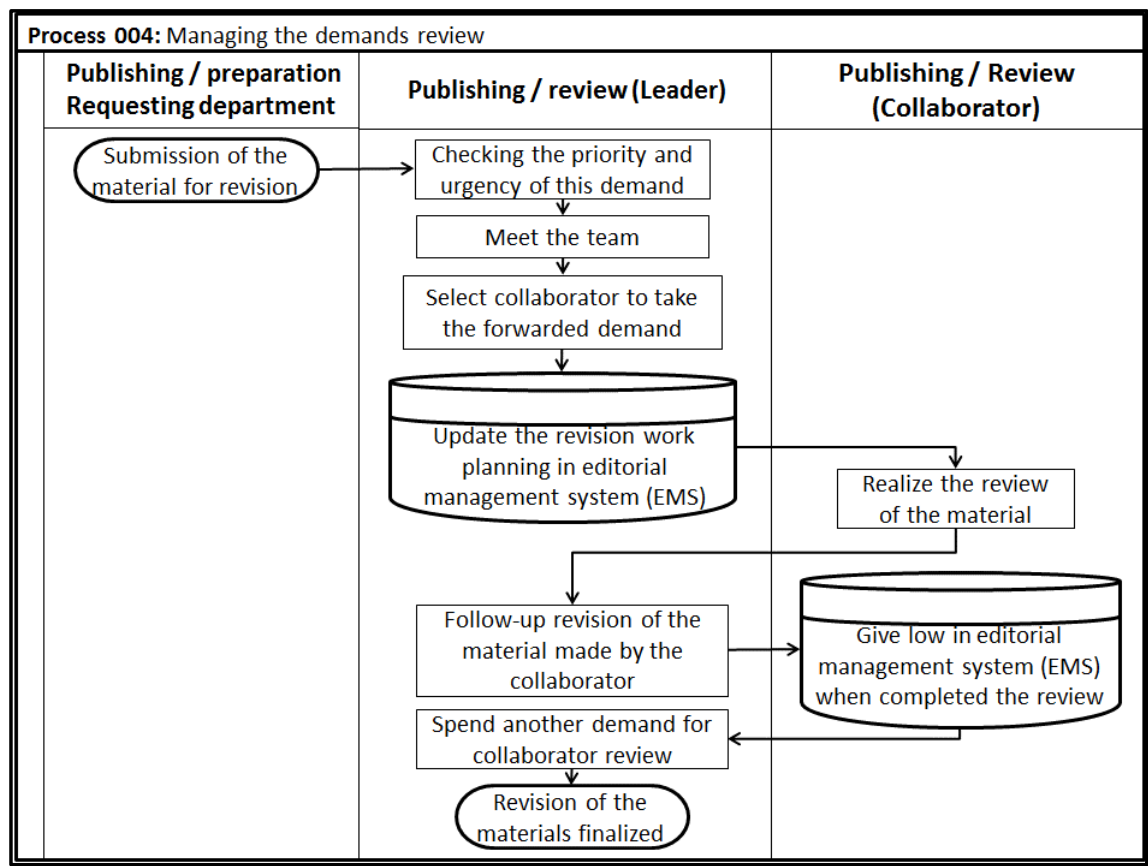

Figure 4. Managing the demands review. Source: Surveyed - higher education institution (HEI).

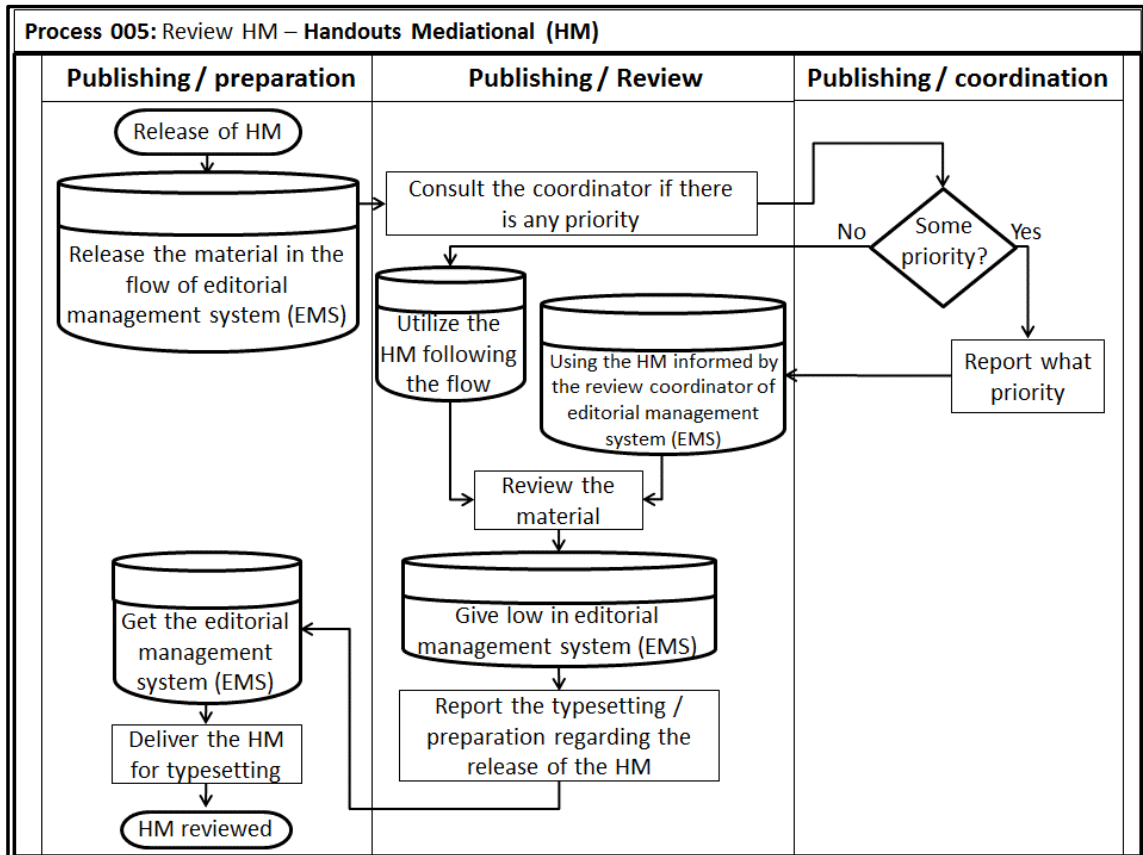

Figure 5. Review handouts mediational. Source: Surveyed-higher education institution (HEI).

In the process 007 , the course coordinator should perform the review of handouts mediational in accordance with the deadline set in the schedule, with the responsibility to resend the material for the core diagramming.

The core of diagramming submits the revised material through the system to the coordinator to validate the changes suggested.

Once approved, the core diagramming releases the content to be sent to the student according to Figure 7. 


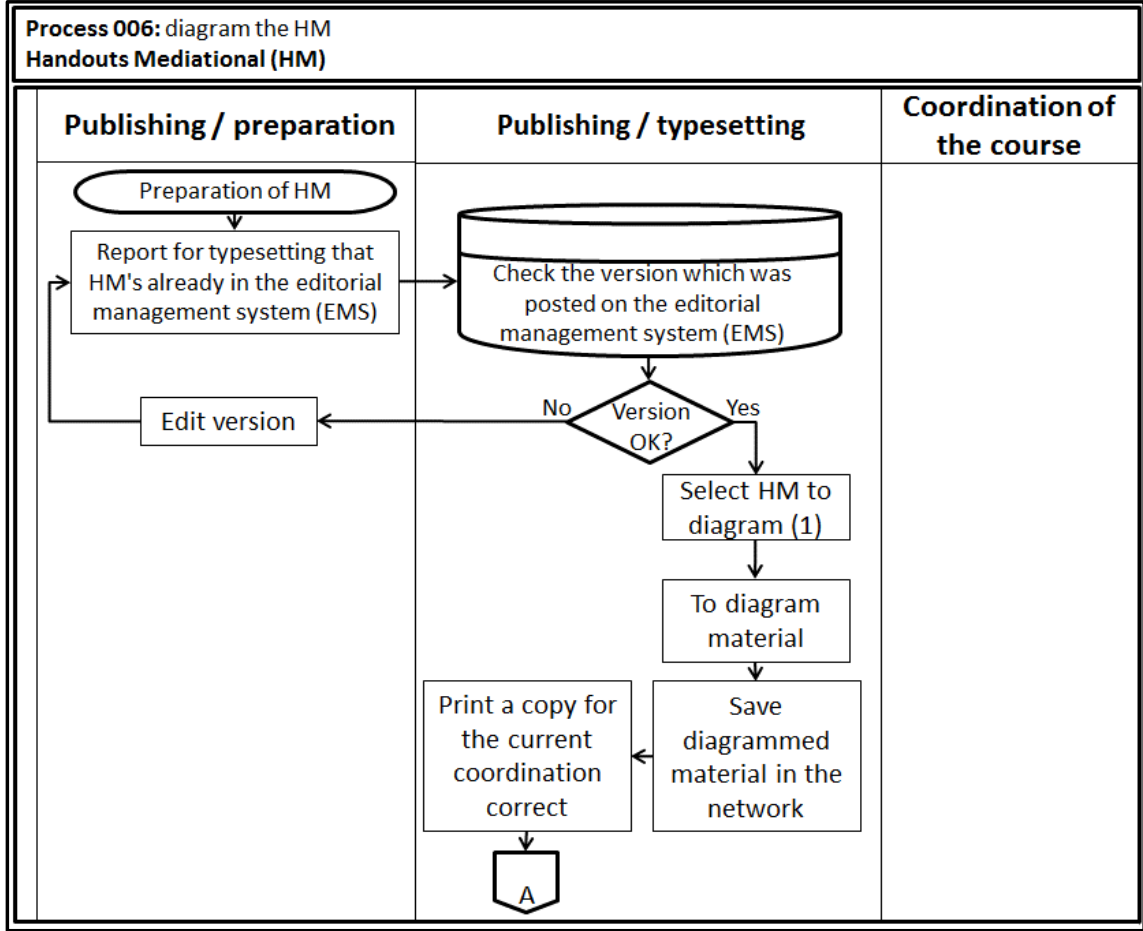

Figure 6. Diagram the handouts mediational (1). Source: Surveyed-higher education institution (HEI).

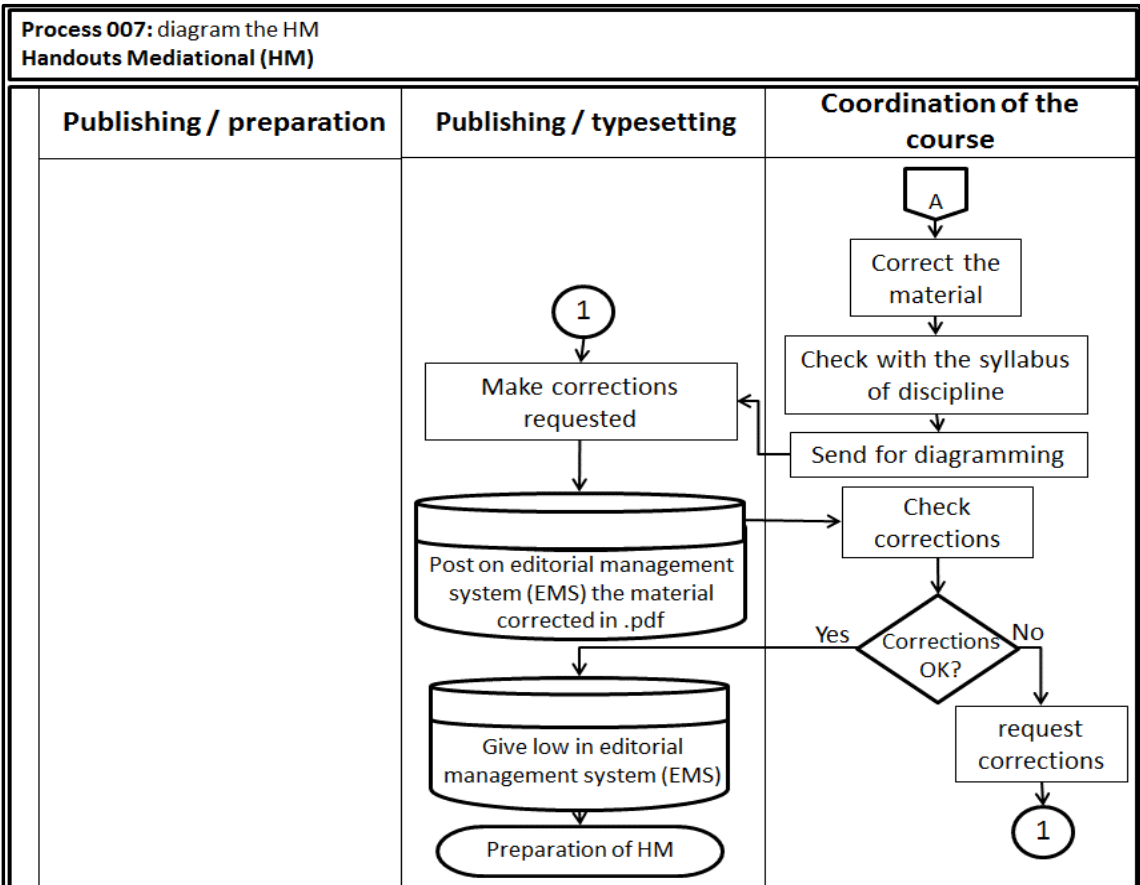

Figure 7. Diagram the handouts mediational (2). Source: Surveyed-higher education institution (HEI).

\section{Editorial Management System (EMS)}

Given the need to control production data, the editorial management system (EMS) was developed.

This system controls the editorial process and contracts, generating reports and monitoring the production, 
providing production management of educational content in order to be carefully designed, planned, designed, and constructed taking account tools for assessment of Brazil's Ministry of Education and the Mission's HEI (Retrieved from http://portal.inep.gov.br/visualizar). The EMS was built to control all stages of design, development, and reproduction of printed and digital materials and also control tasks and dates of copyright contracts salaries, contracts, and payments of outsourced working in the publishing industry.

One of the main features is the ability of accessing the application from anywhere and at any time, due to the materials demand.

The professionals take part of the work to be done outside the institution and outside their working hours, so there is no need to install the system on computers, centralizing the database on a web server.

The system now watches the following controls:

- user access control: insert, update, and delete user groups;

- $\log$ management: to manage operations performed by the user;

- access by different types of professionals and employees, authors, and coordinators;

- management of materials produced by discipline;

- contract management and authors' payments;

- control of the material quality management;

- course reports issue;

- discipline reports issue;

- meeting reports issue;

- issuance of material situations report.

Among the report options, the issue of procurement reports is most frequently used, issuing the types of contracts, their maturing, and pending payments made to authors and payments stands out.

The process 008 shows the system sequence of actions for the registration of the subject in the course and the preparation of tasks in the materials according to Figure 8.

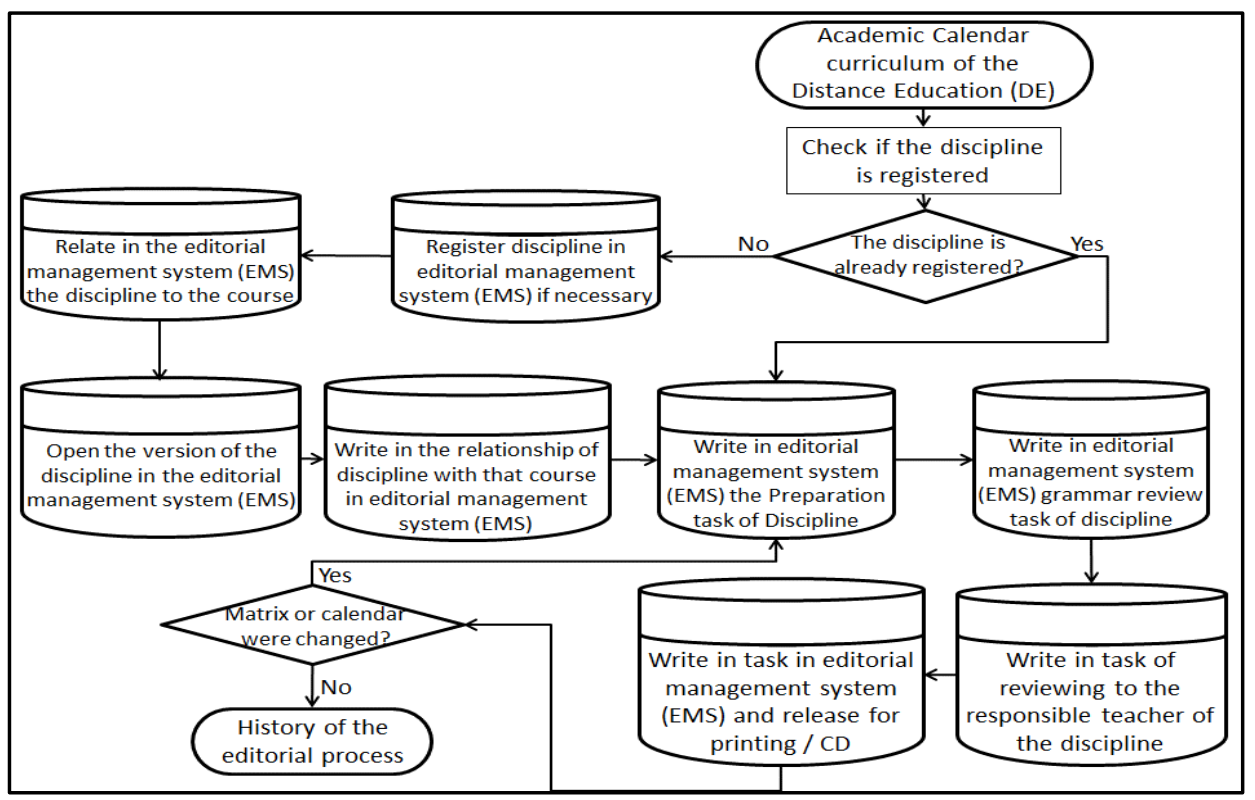

Figure 8. Process 008. Source: Surveyed-higher education institution (HEI). 


\section{Execution of Cubes}

Figure 9 shows the BI environment in which the decision maker can manipulate cubes in order to demonstrate the search results. The setting can be changed and kept for future analyses.

The results of the metric "days_after_deadline" represent the sum of total days for each task of production where the delivery date was later than the stipulated time.

The metric "value_tasks" is the overall value of the tasks related to the annual production of handouts mediationa.

For a better understanding of the interface, the explanations described below are organized according to these numbers:

(1) SGE_See_4_5: This folder created to receive the cubes-editorial management system (EMS). This name was given to the folder, because the version 4.5 of the Pontifical Catholic University (PUC) was the one that worked best. In Mondrian Pentaho Schema Workbench (PSW) when the cubes published, this folder was chosen to store them on the server.

(2) Cubes: Cubes are the files saved within the SGE_See_4_5 folder. The cube file shown in Figure 9 was the file "Measures Graphic by Year". Setting this cube, it was crafted in order to generate the report only the data sum of metrics per year between the years 2010 and 2013.

(3) Cubes run in report form: This cube is without expanding any of its filters. From this macro analysis, you can make hundreds of manipulations, crossing the data and generating information to help in decision-making.

(4) Graphic: The graphic will accompany the filtering cube. Two graphs generated represent the two metrics.

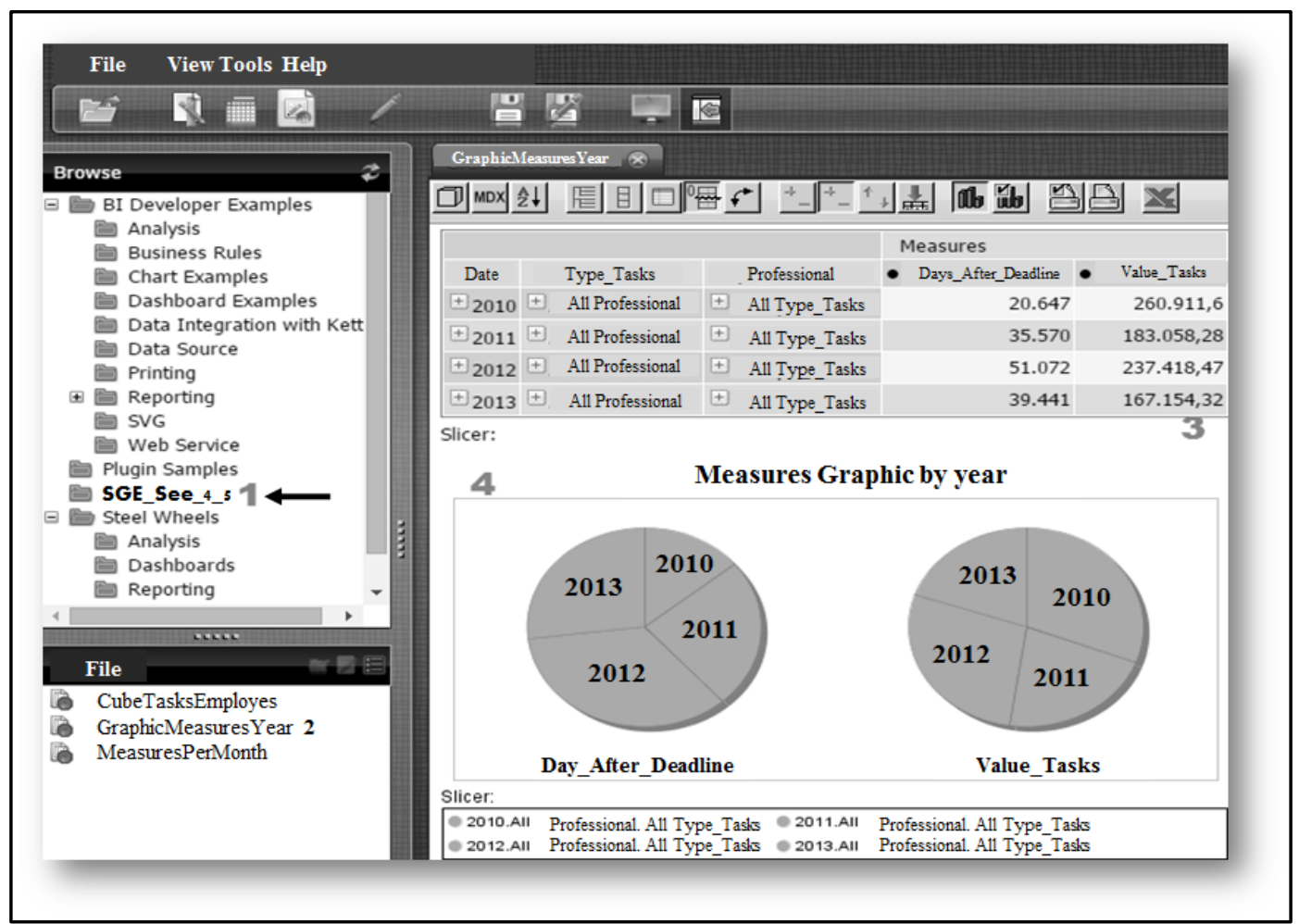

Figure 9. User's view of the cube and generated graph. 


\section{Results Can Be Obtained With the Cube}

It is possible to cross various kinds of filtering the cube. Some examples are as follow:

- filter the sum of the overall metrics for the months of a given year;

- performance of a certain employee during the months of the year;

- comparison of costs of a type of task between years or between the months of a year;

- general survey task per day in a month.

In addition to these crossings, the manager may use the cubes to promote employees who have higher productivity.

You can generate the graphic of results to present to the board increasing the amount of production tasks over the years, seeking to claim the hiring of more employees for the sector.

\section{Testing and Validation of Data}

When the cubes were ready and available for testing, the manager of the materials production sector made the validation of the data and returned (feedback) responding to an evaluation questionnaire based on international standards of software use.

The ISO (International Organization for Standardization) is a non-governmental organization of society, independent, and world's largest developer of voluntary international standards. Headquartered in Geneva, Switzerland, it includes 165 partner countries (ISO 2014).

The ISO/IEC 25010 standard is one of the rules that define how the usability and capability of the software to be understood, learned, used, and to be attractive to the user in specific use conditions software (Dyczkowski, Korczak, \& Dudycz, 2014). Among the quality models that are most often used to evaluate software, the ISO 25010 standard defines the use of the software product, forming a model of five characteristics for use in software products systems (Levy \& Gamboa, 2013).

Polillo (2012) analyzed the ISO/IEC 25010 software and identified five evaluation criteria. Among them, he cited effectiveness, efficiency, and satisfaction in a specified context of use. Figure 10 represents these five characteristics.

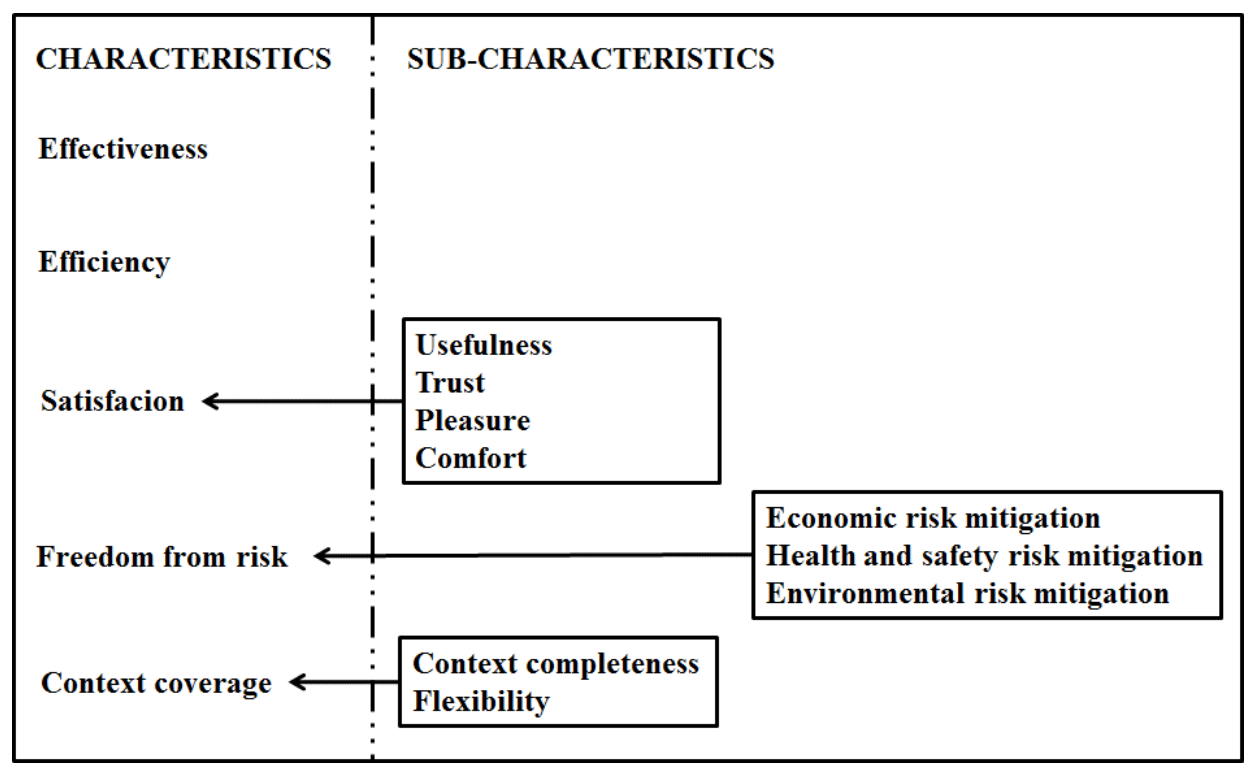

Figure 10. Use of software quality according to ISO/IEC 25010. Source: Polillo (2012). 
Based on Figure 10 of Polillo (2012) for the context of effectiveness software, issues were compiled for the tests with the information generated by cubes:

(1) The results meet expectations;

(2) BI system is easy to use;

(3) There have been difficulties in the use of software.

To address the concept of efficiency, questions were prepared:

(1) Making a relationship between the results obtained and the resources used is to implement a system based on free software platform, in this case: as the publishing industry interprets the cost and benefit, given the ease of implementing a BI system without investments in software;

(2) As the information generated by the cubes, it can assist in making future decisions of the publishing industry as regards the production of materials.

To address the concept of satisfaction (Satisfaction), questions were prepared:

(1) Have the promised results in the case of cubes that generated information about the metrics of production tasks been met? There was satisfaction with the results;

(2) Do the metrics help when filtered by year, month, and type of task or professional;

(3) What reports are created with the use of cube filters;

(4) What other sectors of the institution could take advantage of this technology and how;

(5) Is any experience gained in testing and validation, as BI can help an organization to excel compared to the market competitors?

After the development of the computational tool for BI, the next step was to obtain the data from the records of the transactional system of the educational institution, only the records of distance-learning courses. From the access to data, in order to identify potential inconsistencies or redundancies from the grouping of records, the authors of this work checked with the technicians responsible for database as a maintenance of the following issues:

(1) You confirm that these records did have inconsistencies in their data;

(2) The information generated by the cubes is reliable;

(3) When triggered the filters, the cubes take in return the expected information on the new filtering.

To address the concept of completeness of context and flexibility (context coverage), the issues were elaborated:

(1) Once the BI server was available to be accessed via IP over the wireless network, it was difficult to run other computer systems;

(2) The BI is designed on process 008 . There was an access to the BI system through computers or other operating systems.

Regarding the answers of the tests applied to users, in order to evaluate the proposed system, so far the results positively meet the objectives to been achieved with the use of $\mathrm{BI}$ in this study.

This observation guided the development of the project with the emphasis to support the measurement of production time and the identification of the benefit of using a BI free software in educational material production sector of distance learning, in order to minimize restrictions flow. It is as future work to evaluate the effective use of $\mathrm{BI}$ as the effective reduction of production time and process operating costs from the BI use. 


\section{Sector Return on the Testing and Validation of BI System}

Sector return on the testing and validation of BI system is replying in the material production sector manager on the tests.

About effectiveness. It includes the followings:

(1) Did the results meet expectations?

The filters generated by cubes responded well, providing information on production tasks, however, due to the specificity of the EMS, it can fully meet the industry if they are designed more cubes over other industry data.

(2) Is the BI system easy to use?

Yes, EMS users would have no difficulty using the Pentaho.

(3) Have been any difficulties in the use of software?

There were some doubts regarding the creation of new reports, if necessary.

About efficiency. It includes the followings:

(1) Making a relationship between the results obtained and the resources used is to implement a system based on free software platform, in this case: as the publishing industry interprets the cost and benefit, given the ease of implementing a BI system without investments in software. Regarding cost and benefit, Pentaho was evaluated positively, being easy to use, not having investment in software license purchases. It is believed that, with more time access to cubes however, there will be a better understanding of the size and resources that Pentaho offers.

(2) Is the information generated by the cubes able to assist in making future decisions of the publishing industry as regards the production of materials?

(3) An example of results presented in cubes was information that shows all the work produced by period and production capacity of each employee. This kind of information gives foundation for initiatives to improve production time.

Satisfaction. It includes the followings:

(1) Have the promised results in the case of cubes that generated information about the metrics of production tasks been met? Was there satisfaction with the results?

Yes, the cubes show all work produced by period and production capacity of each employee.

(2) Is the metrics helpful when filtered by year, month, and type of task or professional?

Filters period shows by, e.g., increasing the volume of materials produced between one year and another; this information indicates that there is a need for new hires.

(3) What reports are created with the use of cube filters?

Materials reports produced by period, production capacity of employees and amount of tasks delivered inside and outside the stipulated time.

(4) What other sectors of the institution could take advantage of this technology, and how?

It cannot be told for sure, because the systems of other sectors are not known very well, but authors believed that cubes could be used to signal, for example, the amount of enrollment among school years, filtered by poles of the institution and courses.

(5) With any experience gained in testing and validation, is BI able to help an organization to excel compared to the market competitors? 
This is a difficult question to answer why the publishing industry is part of an institution with many other sectors, which also generate results that influence market indicators. The EMS was developed specifically for this institution.

It is impossible to measure the use of the BI regarding how it could influence, for example, the reduction value of tuition.

Security. Before deploying BI, some cleaning records of production tasks that were allegedly inconsistent have been made:

(1) Did you confirm that these records have inconsistencies in their data?

Yes, the inconsistency was inevitable due to changes in processes and entry and exit of employees in the sector, and some flaws in EMS.

(2) Is the information generated by the cubes reliable?

The information generated by cube has the same reliability of the EMS, but in greater detail.

(3) When triggered the filters, did the cubes take in return the expected information on the new filtering?

No, in testing authors made the time to return the filtered results was almost immediate.

Completeness of context and flexibility. It includes the followings:

(1) Once the BI server is available to be accessed via IP over the wireless network, was it difficult to run other computer systems?

No, entering the IP address of the server in the browser address bar was enough to access the Pentaho.

(2) The BI is designed on process 008. Was there an access to the system via computers with other operating systems?

Yes. One of the computers on which they were made the tests has the Mac OS.

\section{Discussion and Analysis of Responses}

Analyzing in a general context among the surveyed quotes and the questionnaire, a BI system applied through the Pentaho suite can be considered as the following:

(1) effective: because it generates results that meet expectations. Technically it is easy to operate; however, it is necessary to apply training end users for better understanding of research and creation of new cubes.

(2) economic: because it is free software for making efficient flexible custom configuration. The cubes provide information with potential to influence decision making. The responses are quick.

(3) It brings satisfaction to produce information consistent with the data registered in the system through their filters, enabling creation of new reports. It is a system that can be applied in various sectors of an institution.

(4) It provides security on the information returned reliable results and flexibility to work in different operating systems.

\section{Negative Factors}

Among the negative factors, the difficulty of an end user to understand the purpose of the cubes is seen. As end users are accustomed to traditional systems reports, it has to be a paradigm shift to better understand the cubes, so that the BI user seeks to use it always thinking about the data in a multidimensional way.

Another negative point found was the difficulty of finding an ideal version of Pentaho suite for Windows 8 . The Pentaho suite worked well, but their software is not the same version. 
At deployment, some software did not work properly. Therefore, it spent up much time with facilities to reach an ideal setting.

\section{Conclusions}

This paper presents the description of the management process on controlling and monitoring related to the stages of processes execution: publishing and typesetting in an industry responsible for producing learning materials for courses of DE in an HEI in Brazil. It is, therefore, a group of seven consecutive processes that converge to a data structure defined as consolidation process (Figure 8).

In this case, the group of seven consecutive processes to be widely operated in the editorial management process of the educational institution object of study, through the use of the BI environment proposed, should provide greater control of production lead time and thus reduce operating costs, without financial investment in the acquisition of software, because it is a free software.

This is the trade-off mentioned; although it has not yet been measured as to optimize the use of production resources involved, with emphasis on reducing the lead time, it should be significant, simply because the educational institution did not have to make any financial investment in the purchase of software license and the outcome of their application could be a greater control of operating costs with reduced of operation time.

In this context, Watson and Wixom (2007) defined BI as widely used to describe analytic applications, according to the purpose of the BI proposed in this paper, which should guarantee the trade-off described due to the possibility of reducing production-operating costs.

Watson and Wixom (2007), within this perspective, considered that the BI is currently the top-most priority of many chief information officers and it has become a strategic initiative and recognized by chief information officers (CIOs) and business leaders as instrumental in driving business effectiveness and innovation.

In that way, the application of BI concepts in the process of an editorial department of a HEI focused on the development of teaching materials for the courses of DE and identified the financial cost-benefit ratio for the HEI with the deploying BI in a software fee platform in its publishing department. The sector is responsible in courseware publishing organizations that usually do not have systems with this emphasis: support on making managerial decisions.

Among the objective set out in the paper, to demonstrate the impact of using BI's concepts, the fact is that the seven related processes converge into the process 8; although the proposed model of BI is a consolidation of data, the phase of deployment shows that there are great possibility of a positive impact on the production of teaching materials for distance learning due to providing greater visibility and control throughout the flow and that are clearly identified in the data structure shown in Figure 8.

In this case, an effort of the employees involved in the project is necessary, in order to study in detail every step of the publishing process to develop the most consistent flow of information as possible to the design, ensuring an effective control of the process and the possibility of generating concise data with high standard of quality to the management generation reports. All development and structuring of processes eventually generate a learning to the group of employees involved, from teachers to administrative staff and employees of the IT area, as the learning with emphasis on open source and the learning on processes specialists of BI, as the model of development based on the concepts BI applied, their integration into software and application, therefore reducing the effective cost of operation, even if not quantified in this study. This 
paper proves to be significant to the HEI, because no cost of development or investment was required to develop the BI's model proposed, with the prospect of significant gains in the flow of the publishing process and typesetting as a whole, involving opportunities for the reduction of publishing time due to more effective control of all related steps, by ensuring shorter terms and making the control levels of the authors, more effective.

\section{References}

Agdas, D., Washington, S., Ellis, R., Agdas, S., \& Dickrell, P. (2014). Analysis of distance learner value assessment of distance education in engineering. Journal of Professional Issues in Engineering Education and Practice, 140, 1-8.

Aliaga, F. M. (2014). Twenty years of electronic publishing and open access: A pioneer reaches maturity. Revista Electrónica De Investigación Y Evaluación Educativa, 20(1), 1-9.

Azmaa, F., \& Mostafapourb, M. A. (2011). Businesss intelligence as a key strategy for development organizations. Procedia Technology, 1, 102-106.

Bose, I. (2006). Deciding the financial health of dot-coms using rough sets. Information \& Management, 43, 835-846.

Brazil's Ministry of Education. (2014). Instrumento de Avaliação de Cursos de Graduação presencial e a distância. Retrieved from http://portal.inep.gov.br/visualizar

Castellanos, M., Gupta, C., Wang, S., \& Daya, U. (2012). A platform for situational awareness in operational BI. Decision Support Systems, 52, 869-883.

Chou, D. C. (2013). Risk identification in green IT practice. Computer Standards \& Interfaces, 35, 231-237.

Dyczkowski, M., Korczak, J., \& Dudycz, H. (2014). Multi-criteria evaluation of the intelligent dashboard for SME managers based on scorecard framework. Proceedings from the 2014 Federated Conference on Computer Science and Information Systems.

Faucheux, S. A., \& Nicolaï, I. B. (2011). IT for green and green IT: A proposed typology of eco-innovation. Ecological Economics, 70, 2020-2027.

Gao, G. H., Li, N., Xiao, W. X., \& Wan, W. L. (2012). The study on the development of internet-based distance education and problems. Energy Procedia, 17, 1362-1368.

Heiner, L. (2013). Industrial intelligence-A business intelligence-based approach to enhance manufacturing engineering in industrial companies. Proceedings from 8th CIRP Conference on Intelligent Computation in Manufacturing Engineering. Stuttgart-Germany.

Hunter, B. (2013). The effect of digital publishing on technical services in university libraries. The Journal of Academic Librarianship, 39, 84-93.

Isik, O., Jones, M. C., \& Sidorova, A. (2013). Business intelligence success: The roles of BI capabilities and decision environments. Information \& Management, 50, 13-23.

Kaya, M. (2012). Distance education systems used in universities of Turkey and Northern Cyprus. Procedia-Social and Behavioral Sciences, 31, 676-680.

Kim, S. (2007). IT compliance of industrial information systems: Technology management and industrial engineering perspective. The Journal of Systems and Software, 80, 1590-1593.

Kutluk, F. A., Gulmez, M., \& Sidorova, A. (2012). Research about distance education students: Satisfaction with education quality at an accounting program. Social and Behavioral Sciences, 46, 2733-2737.

Lenar, S., Artur, F., Ullubi, S., \& Nailya, B. (2014). Problems and decision in the field of distance education. Social and Behavioral Sciences, 131, 111-117.

Levy, S., \& Gamboa, F. (2013). Quality requirements for multimedia interactive informative systems. Journal of Software Engineering and Applications, 6(8), 416-425.

Lin, C. C., Chiou, W. C., \& Huang, S. S. (2013). The challenges facing e-book publishing industry in Taiwan. Procedia Computer Science, 17, 282-289.

Mcbride, N. (2014). Business intelligence in magazine distribution. International Journal of Information Management, 34, 58-62.

Phan, D. D., \& Vogel, D. R. (2010). A model of customer relationship management and business intelligence systems for catalogue and online retailers. Information \& Management, 47, 69-77. 
Pimentel, L. O., \& Silva, C. E. R. (2014). Software legal concept, proprietary and free standard: Public policies. Sequência (Florianópolis), 68, 291-329.

Polillo, R. (2012). Quality models for web [2.0] sites: A methodological approach and a proposal. Retrieved from http://gplsi.dlsi.ua.es/congresos/qwe11/fitxers/QWE11_Polillo.pdf

Rubin, E., \& Rubin, A. (2013). The impact of business intelligence systems on stock returns volatility. Information \& Management, 50, 67-75.

Sen, B., \& Ucar, E. (2012). Evaluating the achievements of computer engineering department of distance education students with data mining methods. Procedia Technology, 1, 262-267.

Seven, M., Çinar, F. İ., Fidanc1, B. E., \& Akyüz, A. (2014). A Turkish study of nurses' attitudes towards graduate distance education. Procedia-Social and Behavioral Sciences, 116, 3898-3901.

Silva, C. I., \& Almeida, J. (2009). Software studies in action: Open source and free software in Brazil. Retrieved from http://escholarship.org/uc/item/39z4c0v0

Stallman, R. (2015). Information for maintainers of GNU software. Retrieved from http://www.gnu.org/prep/maintain/maintain.pdf

Steiniger, S., \& Hunter, A. J. S. (2012). The 2012 free and open source GIS software map-A guide to facilitate research, development, and adoption. Computers, Environment and Urban Systems, 17(1), 137-148.

Watson, H. J., \& Wixom, B. H. (2007). The current state of business intelligence. Browse Journals \& Magazines, 40(9), 96-99.

Yu, J. C., Yang, H. J., Kuo, L. H., \& Yang, H. H. (2012). Teachers' professional development in free software for education in Taiwan. International Journal of Computers and Communications, 6, 51-59. 